\title{
Olive oil and rapeseed oil differ in their effect on plasma low-density lipoprotein metabolism in the guinea-pig
}

\author{
BY MARIA LUZ FERNANDEZ, ANTHONY E. SOSCIA, GWO-SHING SUN, \\ MARK TOSCA AND DONALD J. MCNAMARA \\ Department of Nutritional Sciences and Interdisciplinary Nutritional Sciences Program, \\ University of Arizona, Tucson AZ 85721, USA
}

AND BRUCE E. MCDONALD

Department of Foods and Nutrition, University of Manitoba, Winnipeg, Canada R3T 2N2

(Received 9 October 1995-Revised 10 April 1996-Accepted 26 April 1996)

\begin{abstract}
The effects of olive oil and rapeseed oil, two different high-oleic-acid oils, on plasma LDL and hepatic cholesterol metabolism were compared in guinea-pigs. Animals were fed on semipurified diet containing $150 \mathrm{~g}$ fat $/ \mathrm{kg}$ as either olive oil (OL), rapeseed oil plus $100 \mathrm{~g}$ palm oil/kg (C-P) or olive oil plus $350 \mathrm{~g}$ safflowerseed oil/kg (OL-S). Olive oil was enriched with safflowerseed oil (OL-S diet) to increase linoleic acid and to decrease palmitic acid concentrations, in order to evaluate whether differences in plasma LDL concentrations were due to intrinsic effects of the specific oil (rapeseed or olive oil) or to differences in the content of specific fatty acids. No differences due to dietary fat source were found in plasma total and HDL-cholesterol levels or in LDL composition. Plasma LDL-cholesterol levels were lower on the C-P diet than the OL diet $(P<0.05)$ while plasma LDL-cholesterol levels in animals fed on the OL-S diet were not significantly different from either dietary group $(P>0.05)$. The number of hepatic apo $B / E$ (LDL) receptors was on average $25 \%$ higher in animals fed on the C-P diet compared with those fed on diets containing olive oil. Likewise, cardiac muscle lipoprotein lipase (EC 3.1.1.34) activity was significantly higher in the C-P group than in the OL and OL-S dietary groups. Dietary fat source had no effect on hepatic cholesterol levels or 3-hydroxy-3-methylglutaryl (HMG) CoA reductase $(E C$ 1.1.1.34) activity. The results indicate that olive oil and rapeseed oil, both rich sources of monounsaturated fatty acids, differ in their efiect on LDL metabolism in the guinea-pig.
\end{abstract}

Low-density lipoprotein: Rapeseed oil: Lipoprotein lipase

The prevailing theory up to 1985 held that dietary saturated fatty acids raised, polyunsaturated fatty acids lowered and monounsaturated fatty acids had essentially no effect on plasma cholesterol levels in humans (Hegsted et al. 1965; Keys et al. 1965; McNamara, 1992). However, the report that high-oleic safflowerseed oil was as effective as traditional safflowerseed oil in reducing plasma total and LDL-cholesterol levels in humans (Matson \& Grundy, 1985) suggested that the relationship between dietary fat saturation and cholesterol metabolism is more complex than originally postulated. Subsequent studies have shown other oleate-rich oils, e.g. olive oil and rapeseed oil, to be equally as hypocholesterolaemic as linoleate-rich oils, namely soyabean oil, sunflowerseed oil and safflowerseed oil (McDonald et al. 1989; Mensink \& Katan, 1989; Wardlaw \& Snook, 1990; Chan et al. 1991). These findings in human subjects were accompanied by studies in animal models aimed at explaining the effect of dietary fat level and composition on cholesterol metabolism (Spady \& Dietschy, 1988; Fernandez \& McNamara, 1991; Daumerie et al. 1992; Fernandez et al. 1992). 
The guinea-pig has been a useful animal model to study the effect of diet on cholesterol metabolism because of similarities to humans in terms of plasma lipoprotein profiles, effect of type and amount of dietary fat on the pattern of lipoprotein responses, rates of hepatic cholesterol synthesis, and distribution of hepatic cholesterol pools (Fernandez et al. 1990, 1992; Fernandez \& McNamara, 1991, 1994). However, plasma total and LDL-cholesterol changes in the guinea-pig in response to olive oil (Fernandez \& McNamara, 1989; Fernandez et al. 1990) were not the same as those observed in humans (Mensink \& Katan, 1989) although not all studies have found olive oil equal to oils rich in polyunsaturated fatty acids in lowering plasma total and LDL-cholesterol levels in human subjects (Sirtori et al. 1986; Mata et al. 1992). Furthermore, Lichtenstein et al. (1993) reported that olive oil was not as effective as rapeseed oil or maize oil in lowering plasma total and LDLcholesterol levels in moderately hypercholesterolaemic human subjects fed on low-fat, low-cholesterol diets ( $<30 \%$ energy as fat, $<7 \%$ as saturated fat and $<200 \mathrm{mg}$ cholesterol/d). The present study was undertaken to test the hypothesis that a rapeseed-oil-based diet results in lower plasma LDL-cholesterol levels than an olive-oil-based diet in guineapigs (Fernandez \& McNamara, 1989; Fernandez et al. 1990), and to determine whether such differences in plasma cholesterol concentrations are accounted for by modifications in specific variables which determine plasma lipoprotein levels and metabolism.

\section{MATERIALS AND METHODS}

\section{Materials}

Cholesterol and triacylglycerol enzymic assay kits were obtained from BoehringerMannheim (Indianapolis, IN, USA); fatty acids standards from Supelco, Inc (Bellefonte, PA, USA); free cholesterol and phospholipid enzymic kits from Waco Pure Chemical Industries, Ltd (Osaka, Japan); ${ }^{121} \mathrm{I}-\mathrm{Na}$ from Amersham (Clearbrook, IL, USA), halothane from Halocarbon (Hackensack, NJ, USA); and Quickseal ultracentrifugation tubes from Beckman Instruments (Palo Alto, CA, USA).

\section{Diets}

Diets were prepared and pelleted by Research Diets, Inc. (New Brunswick, NJ, USA). The diets were identical except for fat source, which consisted of $150 \mathrm{~g} / \mathrm{kg}$ diet of either olive oil (OL diet), rapeseed oil-palm oil $(90: 10, \mathrm{v} / \mathrm{v})(\mathrm{C}-\mathrm{P}$ diet), or olive oil-safflowerseed oil $(65: 35, \mathrm{v} / \mathrm{v})$ (OL-S diet) (Table 1). Palm oil was added to the rapeseed-oil diet because rapeseed oil is appreciably lower in saturated fatty acid content than olive oil. Likewise, safflowerseed oil was added to the olive oil to increase the polyunsaturated fatty acid content of the diet. Lipid was extracted from the diets with chloroform-methanol $(2: 1$, $\mathrm{v} / \mathrm{v}$ ) and the fatty acid composition of the dietary fat (Table 2) determined by GLC as described previously (Fernandez \& McNamara, 1989).

\section{Animals}

Male Hartley guinea-pigs (Sasco Sprague Dawley, Omaha, NE, USA) weighing 500-650 g were assigned randomly to one of the three dietary groups. They were housed in a room with controlled light cycle (light 07.00 to 19.00 hours). Free access to diet and water was provided for 4 weeks and animals were weighed weekly to assess feed consumption. At the end of the experimental period, non-fasted animals were anaesthetized with halothane vapours and killed by exsanguination via cardiac puncture, and livers were excised for further analysis. A portion (about $2 \mathrm{~g}$ ) was refrigerated at $4^{\circ}$ for determination of hepatic cholesterol and the rest was used for isolation of hepatic membranes and microsomes which were kept at $-70^{\circ}$ for subsequent determinations of LDL-receptor number and 3-hydroxy 
Table 1. Composition of diets

\begin{tabular}{llcl}
\hline Ingredient & $\begin{array}{c}\text { Amount } \\
(\mathrm{g} / \mathrm{kg})\end{array}$ & $\begin{array}{c}\text { Energy } \\
(\%)\end{array}$ \\
\hline Soyabean protein & 217 & 23 \\
L-Methionine & 5 & 36 \\
Fat (OL, C-P or OL-S)* & 151 & 24 \\
Sucrose & 233 & 24 \\
Maize starch & 163 & 17 \\
Cellulose & 109 & \\
Guar gum & 27 & \\
Minerals $\dagger$ & 82 & \\
\hline
\end{tabular}

* Fat sources: olive oil (OL); rapeseed oil-palm oil (90:10, v/v; C-P); olive oil-safflowerseed oil (65:35, v/v; OL-S).

$\dagger$ Vitamins and minerals were added at levels recommended for the guinea-pig by the National Research Council (for details, see Fernandez \& McNamara, 1991).

Table 2. Fatty acid composition of experimental diets $(\mathrm{g} / 100 \mathrm{~g}$ total fatty acids)

(Values are means of two determinations)

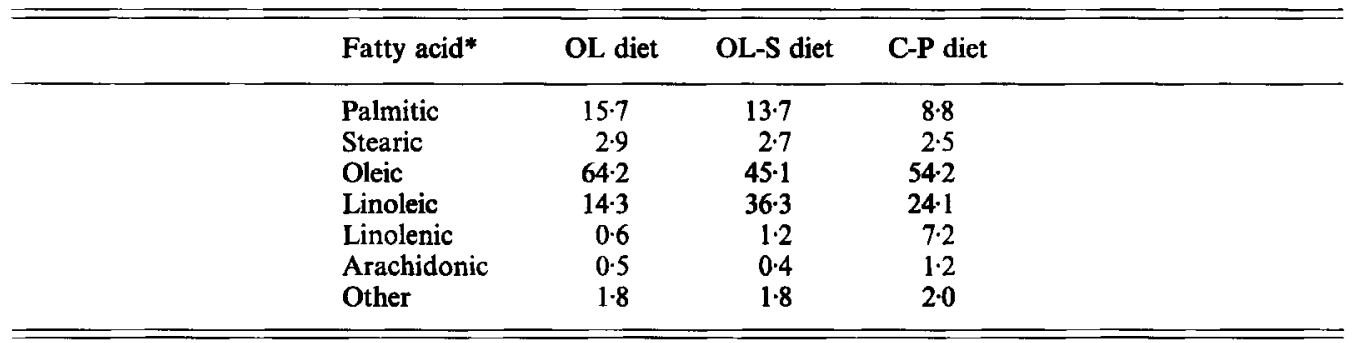

OL; olive oil; OL-S, olive oil-safflowerseed oil; C-P, rapeseed oil-palm oil.

* $\Sigma$ Saturated fatty acids: $18 \cdot 6,15 \cdot 8$ and $11 \cdot 3 ; \Sigma$ monounsaturated fatty acids $66 \cdot 5,47 \cdot 3$ and $56 \cdot 7$, and $\Sigma$ polyunsaturated fatty acids $14 \cdot 9,36.8$ and $31 \cdot 3$ for the OL, OL-S and C-P diets respectively.

3-methylglutaryl (HMG) CoA reductase (EC 1.1.1.34) activity. Skeletal and cardiac muscle and adipose tissue used to measure fatty acid composition and lipoprotein lipase (EC 3.1.1.34; LPL) activity were frozen at $-70^{\circ}$ before analysis. The experimental protocol was approved by the University of Arizona Institutional Animal Care and Use Committee; the animal experiments were conducted according to US Public Health Service and US Department of Agriculture guidelines.

\section{Plasma and liver lipids}

Plasma total and lipoprotein cholesterol concentrations were determined by enzymic analysis (Allain et al. 1974). Lipoproteins were separated by sequential ultracentrifugation (Model L8-M ultracentrifuge, Beckman Instruments, Palo Alto, CA, USA) at $125000 \mathrm{~g}$ at $15^{\circ}$ for $19 \mathrm{~h}$ in a Ti-50 rotor. Separation of the lipoprotein fractions was based on the following densities $(\rho): \rho=1.006-1.019 \mathrm{~kg} / \mathrm{l}$ for VLDL + intermediate density lipoproteins (IDL); $\rho=1.019-1.090 \mathrm{~kg} / 1$ for LDL; and $\rho=1.090-1.120 \mathrm{~kg} / \mathrm{l}$ for HDL. Isolated LDL were analysed for protein, free and esterified cholesterol, triacylglycerol and phospholipids as described previously (Fernandez \& McNamara, 1989). Hepatic concentrations 
of total and free cholesterol were determined by the method of Carr et al. (1993) and the cholesteryl ester levels derived by subtracting free from total cholesterol.

\section{Determination of adipose-tissue fatty acids}

Total lipids were extracted from guinea-pig epididymal adipose tissue and fatty acids were converted to fatty-acid methyl esters (FAME) by base-catalysed transesterification with sodium methoxide. FAME were separated by GC using a Packard gas chromatograph (Model 438A, Chromopack, Raritan, NJ, USA) equipped with a Supelco SP-2380 (Bellefonte, PA, USA) wide-bore capillary column, $30 \mathrm{~m} \times 0.53 \mathrm{~mm}$, using temperature programming with an initial temperature of $90^{\circ}$ and a final temperature of $240^{\circ}$. Helium was the carrier gas at a flow rate of $5 \mathrm{ml} / \mathrm{min}$. Peaks were identified by comparison of retention times with standards and fatty acids were quantified on the basis of area under the peak compared with standards.

\section{Hepatic hydroxy methylglutaryl-CoA reductase assay}

Hepatic microsomes for measurement of $\mathrm{HMG}-\mathrm{CoA}$ reductase were isolated as described by Nordstrom et al. (1977). Microsomal HMG-CoA reductase activity was measured by incubation of $200 \mu \mathrm{g}$ microsomal protein with $7.5 \mathrm{nmol}(0.33 \mathrm{GBq} / \mathrm{nmol})\left[3-{ }^{14} \mathrm{C}\right] \mathrm{HMG}-$ CoA, $4.5 \mu \mathrm{mol}$ glucose 6-phosphate, $3.6 \mu \mathrm{mol}$ EDTA, $0.45 \mu \mathrm{mol}$ NADP and $0.3 \mathrm{IU}$ glucose 6-phosphate dehydrogenase $(E C 1.1 .1 .49)$ in a final volume of $0.20 \mathrm{ml}$ for $15 \mathrm{~min}$ at $37^{\circ}$, using $\left[{ }^{3} \mathrm{H}\right]$ mevalonic acid as an internal recovery standard $(0.024 \mathrm{GBq}$ per assay). $\mathrm{HCl}$ $(25 \mu 1)$ was added to stop the reaction and samples were further incubated for $30 \mathrm{~min}$. After incubation, microsomal protein was pelleted by microfuging for $1 \mathrm{~min}$. A known portion of each supernatant fraction was applied to a TLC silica gel plate (Alltech, Deerfield, IL, USA) and developed in acetone-benzene $(1: 1, v / v)$. The area containing mevalolactone $\left(R_{f} 0.6-0.9\right)$ was removed, mixed with $5 \mathrm{ml}$ aquasol and counted for radioactivity in a scintillation counter. HMG-CoA reductase activity is expressed as pmol $\left[{ }^{14} \mathrm{C}\right]$ mevalonate synthesized/min per mg microsomal protein. Recoveries of the internal standard were between 60 and $80 \%$.

\section{Lipoprotein lipase assay}

Skeletal and cardiac muscle and adipose tissue were isolated from guinea-pigs and LPL activities assayed in the supernatant fraction following homogenization of $1 \mathrm{~g}$ tissue in

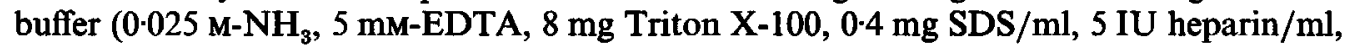
$10 \mu \mathrm{g}$ pepstatin $/ \mathrm{ml}, 25 \mathrm{IU}$ trasylol $/ \mathrm{ml}$ ) and centrifuging at $10000 \mathrm{~g}$ for $20 \mathrm{~min}$ at $4^{\circ}$. The homogenate was incubated with $\left.{ }^{3} \mathrm{H}\right]$ triolein $\left(50 \times 10^{6} \mathrm{dpm}\right)$ for $30 \mathrm{~min}$ at $25^{\circ}$ in a water bath and reactions stopped by addition of $3.25 \mathrm{ml}$ methanol-chloroform-heptane $(1 \cdot 41: 1 \cdot 24: 1$, by vol.). The methanol-water upper phase was removed and free-fatty-acid radioactivity determined in a scintillation counter. Results are expressed as nmol fatty acid released/min per $\mathrm{g}$ tissue at $25^{\circ}$.

\section{LDL binding assays}

Pooled samples of guinea-pig LDL from each dietary group were radioiodinated with ${ }^{125}$ I by the iodine monochloride method (Goldstein et al. 1983) to give a specific activity. of between 120 and 300 counts/min per $\mathrm{ng}$. Hepatic membranes isolated as previously described (Fernandez \& McNamara, 1989) from animals fed on homologous diet were incubated with the radiolabelled LDL over a concentration range of $10-80 \mu \mathrm{g} / \mathrm{ml}$ in the presence or absence of $1 \mathrm{mg} / \mathrm{ml}$ unlabelled human $\mathrm{LDL}$, an effective competitor at $37^{\circ}$. After incubation, membranes were pelleted and counted. The affinity constant $\left(K_{\mathrm{d}}\right)$ and maximum binding $\left(\mathrm{B}_{\mathrm{max}}\right.$ ) were determined from Woolf plots (Keightley et al. 1983). 
Statistical analysis

One-way ANOVA was used to analyse differences among diet groups. Following the $F$ test, the Newman-Keuls post-hoc test was used to identify significant $(P<0.05)$ differences among means. The Kruskal-Wallis nonparametric ANOVA test was used where indicated. Linear regressions were performed to assess significant correlations.

\section{RESULTS}

Weight gain and final average body weight were not affected by dietary fat source. Final body weights for the dietary groups $(n 9)$ were: OL, 790 (SD 67) g; OL-S, 761 (SD 80) g and C-P, 730 (SD 50) g.

\section{Effect of dietary fat on plasma and lipoprotein cholesterol levels, LDL composition and lipoprotein lipase activity}

There were no significant $(\boldsymbol{P}>0.05)$ differences in plasma total, VLDL- or HDLcholesterol levels due to dietary fat source (Table 3). LDL-cholesterol concentrations were not different between animals fed on the OL and OL-S diets. However, LDL-cholesterol concentrations were $26 \%$ lower in animals fed on the C-P diet compared with those fed on the OL diet $(P<0.05)$ and $23 \%$ lower compared with animals from the OL-S group, although due to the large standard deviation OL-S values were not different from the C-P group (Table 3).

Chemical compositions of the LDL particles did not differ among the dietary groups; the relative proportions of cholesteryl ester, free cholesterol, triacylglycerol and phospholipids were not different for LDL from animals fed on the OL, C-P and OL-S diets (Table 4).

There were no significant differences due to dietary fat source in adipose tissue or skeletal muscle LPL activity $(P=0.07$ and $P=0.09)$ in animals fed on the C-P diet compared with values for tissues from animals fed on the diets containing olive oil (Table 5). Cardiac muscle LPL activity, however, was significantly higher for guinea-pigs fed on the C-P diet than for those fed on the OL and OL-S diets (Table 5).

\section{Effects of dietary fat source on adipose-tissue fatty acid composition}

The fatty acid composition of epididymal adipose tissue was significantly altered by the type of dietary fat. Palmitoleic and oleic acids were highest in animals fed on the OL diet as expected because of the higher percentage of oleic acid in this diet $(P<0.001)$ while linoleic acid was highest in animals fed on the OL-S diet, intermediate for C-P-fed guineapigs and lowest for the OL group, in agreement with the fatty acid composition of the diets (Table 6). Likewise, linolenic acid was significantly $(P<0.0001)$ higher in the C-P group than in the two groups fed on the OL diets, which is consistent with the linolenic acid content of the dietary fats.

\section{Hepatic cholesterol concentrations, hydroxy methylglutaryl-CoA reductase and $L D L$ binding variables}

The type of dietary fat did not affect the concentrations of hepatic cholesterol or the distribution between hepatic free and esterified cholesterol pools (Table 7). Similarly, there were no differences in hepatic HMG-CoA reductase activity among guinea-pigs fed on the three different diets (Table 7).

Dietary fat source had no effect on the affinity $\left(K_{d}\right)$ of the apo B/E receptor for $L D L$ (Table 7). Apo B/E receptor-mediated maximal LDL binding $\left(B_{\max }\right)$ by hepatic membranes, however, was significantly $(P<0.05)$ greater for animals fed on the C-P diet than for those fed on diets containing olive oil (Table 8 ); $B_{\max }$ values were 27 and $20 \%$ higher in animals 
Table 3. Plasma total and lipoprotein cholesterol levels (mmol/l) of guinea-pigs fed on semipurified diets containing $150 \mathrm{~g}$ dietary fat $/ \mathrm{kg}$ as olive oil $(O L)$, rapeseed oil-palm oil $(90: 10, v / v ; C-P)$ or olive oil-safflowerseed oil $(65: 35, v / v ; O L-S)$

(Mean values and standard deviations for nine animals)

\begin{tabular}{|c|c|c|c|c|c|c|}
\hline & \multicolumn{2}{|c|}{ OL diet } & \multicolumn{2}{|c|}{ OL-S diet } & \multicolumn{2}{|c|}{ C-P diet } \\
\hline & Mean & $S D$ & Mean & SD & Mean & SD \\
\hline $\begin{array}{l}\text { Total } \\
\text { VLDL } \\
\text { LDL } \\
\text { HDL }\end{array}$ & $\begin{array}{l}1.76 \\
0.16 \\
1.40^{2} \\
0.21\end{array}$ & $\begin{array}{l}0.25 \\
0.08 \\
0.25 \\
0.05\end{array}$ & $\begin{array}{l}1.73 \\
0.16 \\
1.34^{\mathrm{ab}} \\
0.23\end{array}$ & $\begin{array}{l}0.59 \\
0.08 \\
0.59 \\
0.05\end{array}$ & $\begin{array}{l}1.44 \\
0.15 \\
1.03^{b} \\
0.23\end{array}$ & $\begin{array}{l}0.28 \\
0.04 \\
0.20 \\
0.05\end{array}$ \\
\hline
\end{tabular}

a, b Mean values in the same row with different superscript letters were significantly different $(P<0.05)$ as determined by the Kruskal-Wallis nonparametric ANOVA test.

Table 4. Chemical composition ( $\mathrm{mg} / \mathrm{g}$ ) of plasma low-density lipoproteins from guinea-pigs fed on diets containing $150 \mathrm{~g}$ fat $/ \mathrm{kg}$ as olive oil $(O L)$, rapeseed oil-palm oil $(90: 10, \mathrm{v} / \mathrm{v}$; $C-P)$ or olive oil-safflowerseed oil $(65: 35, v / v ; O L-S)$

(Mean values and standard deviations for five (OL) or six (OL-S, C-P) animals)

\begin{tabular}{|c|c|c|c|c|c|c|}
\hline \multirow[b]{2}{*}{ Component } & \multicolumn{2}{|c|}{ OL diet } & \multicolumn{2}{|c|}{ OL-S diet } & \multicolumn{2}{|c|}{ C-P diet } \\
\hline & Mean & SD & Mean & SD & Mean & SD \\
\hline $\begin{array}{l}\text { Cholesteryl ester } \\
\text { Free cholesterol } \\
\text { Triacylglycerol } \\
\text { Phospholipid } \\
\text { Protein }\end{array}$ & $\begin{array}{r}388 \\
86 \\
87 \\
148 \\
290\end{array}$ & $\begin{array}{r}19 \\
7 \\
15 \\
8 \\
14\end{array}$ & $\begin{array}{r}383 \\
83 \\
92 \\
145 \\
295\end{array}$ & $\begin{array}{r}16 \\
8 \\
15 \\
8 \\
11\end{array}$ & $\begin{array}{r}373 \\
81 \\
99 \\
141 \\
306\end{array}$ & $\begin{array}{r}24 \\
9 \\
16 \\
4 \\
12\end{array}$ \\
\hline
\end{tabular}

Table 5. Lipoprotein lipase (EC 3.1.1.34; LPL) activities (nmol/min per g) of guinea-pigs fed on diets containing $150 \mathrm{~g}$ fat $/ \mathrm{kg}$ as olive oil $(O L)$, rapeseed oil-palm oil $(90: 10, v / v, C-P)$ or olive oil-safflowerseed oil $(65: 35, v / v ; O L-S)$

(Values are means and standard deviations for six determinations)

\begin{tabular}{|c|c|c|c|c|c|c|}
\hline & \multicolumn{2}{|c|}{ OL diet } & \multicolumn{2}{|c|}{ OL-S diet } & \multicolumn{2}{|c|}{ C-P diet } \\
\hline & Mean & SD & Mean & SD & Mean & SD \\
\hline Adipose tissue & 918 & 378 & 889 & 173 & 1285 & 329 \\
\hline Skeletal muscle & 284 & 50 & 300 & 159 & 456 & 173 \\
\hline Cardiac muscle & $6136^{\circ}$ & 944 & $6121^{\circ}$ & 541 & $8016^{a}$ & 644 \\
\hline
\end{tabular}

a, b Mean values in the same row with different superscript letters were significantly different as determined by ANOVA and the Newman-Keuls post-hoc test $(P<0.01)$. 
Table 6. Fatty acid composition of epididymal adipose tissue ( $\mathrm{g} / 100 \mathrm{~g}$ total fatty acids) of guinea-pigs fed on diets containing $150 \mathrm{~g}$ fat/kg as olive oil $(O L)$, rapeseed oil-palm oil $(90: 10, v / v ; C-P)$ or olive oil-safflowerseed oil $(65: 35, v / v ; O L-S)$

(Values are means and standard deviations for six determinations)

\begin{tabular}{|c|c|c|c|c|c|c|}
\hline \multirow[b]{2}{*}{ Fatty acid } & \multicolumn{2}{|c|}{ OL diet } & \multicolumn{2}{|c|}{ OL-S diet } & \multicolumn{2}{|c|}{ C-P diet } \\
\hline & Mean & SD & Mean & SD & Mean & SD \\
\hline $14: 0$ & $1 \cdot 13$ & 0.02 & 1.07 & 0.11 & $1 \cdot 12$ & 0.11 \\
\hline $16: 0$ & $20 \cdot 6$ & 0.6 & $19 \cdot 1$ & 0.4 & $18 \cdot 0$ & 0.8 \\
\hline $16: 1$ & $2 \cdot 34^{c}$ & 0.43 & $1.54^{b}$ & 0.17 & $1 \cdot 19^{b}$ & 0.20 \\
\hline $18: 0$ & $4 \cdot 07$ & 0.81 & 3.85 & 0.33 & 3.97 & 0.42 \\
\hline $18: 1$ & $47 \cdot 3^{a}$ & 1.9 & $37.9^{\mathrm{b}}$ & 1.0 & $42 \cdot 4^{c}$ & 1.0 \\
\hline $18: 2$ & $20 \cdot 1^{2}$ & 1.6 & $32 \cdot 7^{b}$ & 1.4 & $25 \cdot 8^{\mathrm{c}}$ & 0.6 \\
\hline $18: 3$ & $2 \cdot 8^{\mathrm{a}}$ & 0.4 & $2 \cdot 5^{\mathrm{a}}$ & 0.4 & $5 \cdot 8^{b}$ & 0.1 \\
\hline $20: 1$ & 0.5 & 0.03 & 0.5 & 0.06 & 0.7 & 0.02 \\
\hline $20: 2$ & 0.3 & 0.01 & 0.35 & 0.02 & 0.34 & 0.03 \\
\hline Others & 0.84 & $0-35$ & 0.55 & 0.37 & 0.83 & 0.37 \\
\hline
\end{tabular}

$a, b, c$ Mean values in the same row with different superscript letters were significantly different as determined by ANOVA and Newman-Keuls post-hoc test $(P<0.001)$.

Table 7. Hepatic total, free and esterified cholesterol and microsomal 3-hydroxy-3methylglutaryl (HMG)-CoA reductase (EC 1.1.1.34) activity of guinea-pigs fed on semipurified diets containing $150 \mathrm{~g}$ fat $/ \mathrm{kg}$ as olive oil $(O L)$, rapeseed oil-palm oil $(90: 10, v / v$; $C-P)$ or olive oil-safflowerseed oil $(65: 35 ; v / v ; O L-S)$

(Values are means and standard deviations for nine determinations (hepatic cholesterol) or six determinations (HMG-CoA reductase))

\begin{tabular}{|c|c|c|c|c|c|c|c|c|}
\hline \multirow[b]{3}{*}{ Diet } & \multicolumn{6}{|c|}{ Hepatic cholesterol $(\mathrm{mg} / \mathrm{g})$} & \multirow{2}{*}{\multicolumn{2}{|c|}{$\begin{array}{l}\text { HMG-CoA reductase } \\
\text { (pmol/min per } \mathrm{mg})\end{array}$}} \\
\hline & \multicolumn{2}{|c|}{ Total } & \multicolumn{2}{|c|}{ Free } & \multicolumn{2}{|c|}{ Esterified } & & \\
\hline & Mean & SD & Mean & SD & Mean & $\mathrm{SD}$ & Mean & SD \\
\hline OL & 2.53 & 0.14 & $2-39$ & 0.15 & 0.14 & 0.07 & $5 \cdot 4$ & 2.9 \\
\hline OL-S & $2 \cdot 70$ & 0.20 & 2.53 & 0.18 & 0.17 & 0.04 & 5.4 & $3 \cdot 5$ \\
\hline C-P & $2 \cdot 54$ & 0.32 & $2 \cdot 36$ & 0.32 & $0 \cdot 18$ & 0.04 & $4 \cdot 3$ & $1 \cdot 5$ \\
\hline
\end{tabular}

fed on the C-P diet compared with those fed on the OL diet or the OL-S diet respectively. There was a significant negative correlation between plasma LDL-cholesterol concentrations and hepatic receptor $\mathrm{B}_{\max }$ values $(r-0.73, P<0.01$; Fig 1$)$.

\section{DISCUSSION}

It is generally accepted that dietary saturated fatty acids, in particular lauric, myristic and palmitic, predispose to higher plasma total and LDL-cholesterol levels, and that saturated fatty acids in the diet play a major role in the aetiology of cardiovascular disease (McNamara, 1992). Likewise, until recently it was believed that dietary polyunsaturated fatty acids bring about a decrease in plasma total cholesterol whereas monounsaturated fatty acids are neutral, they neither raise nor lower plasma cholesterol levels (Hegsted et al. 
Table 8. LDL binding to hepatic membranes of guinea-pigs fed on diets containing $150 \mathrm{~g}$ fat $/ \mathrm{kg}$ as olive oil $(O L)$, rapeseed oil-palm oil $(90: 10, v / v ; C-P)$ or olive oil-safflowerseed oil $(65: 35, v / v ; O L-S)$

(Values are means and standard deviations for four determinations)

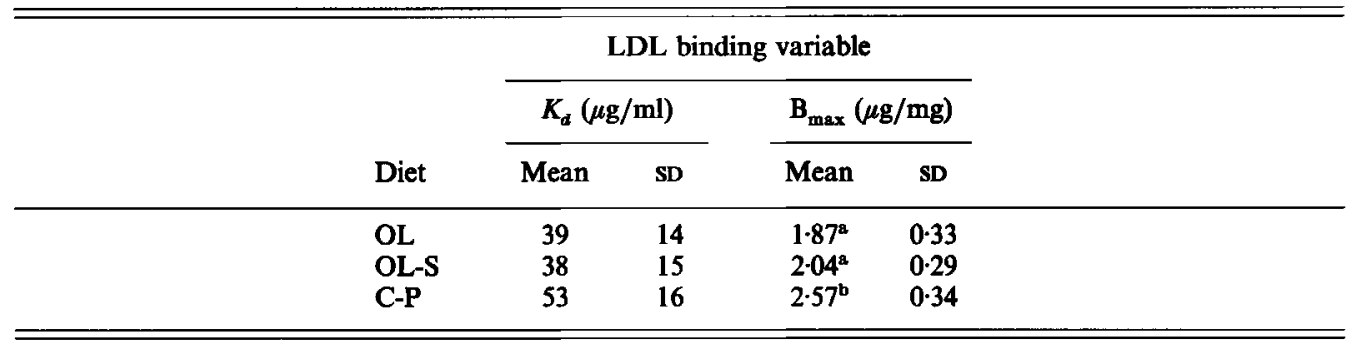

a, b Mean values in the same column with different superscript letters were significantly different $(P<0.01)$ as determined by ANOVA and the Newman-Keuls post-hoc test.

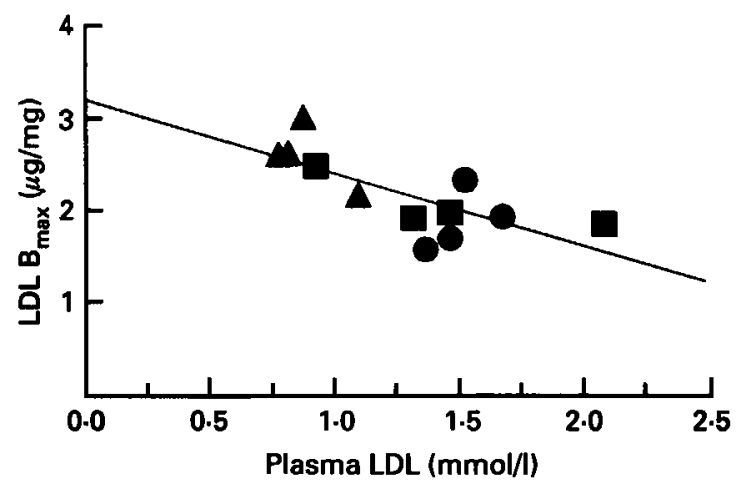

Fig. 1. Correlation between plasma LDL-cholesterol concentration (mmol/1) and hepatic LDL receptor $B_{\max }$ $(\mu \mathrm{g} / \mathrm{mg})$ in guinea-pigs fed on diets containing $150 \mathrm{~g}$ fat $/ \mathrm{kg}$ as olive oil $(\mathrm{O})$, rapeseed oil-palm oil $(90: 10, \mathrm{v} / \mathrm{v})$ (A) or olive oil-safflowerseed oil $(65: 35, \mathrm{v} / \mathrm{v})(\square)(r-0.732, P<0.01)$.

1965; Keys et al. 1965). These basic relationships continue to be supported (Hegsted et al. 1993) in spite of the fact that direct comparisons of diets containing high levels of monounsaturated and polyunsaturated fatty acids show that these are equally effective in lowering plasma total and LDL-cholesterol concentrations in human subjects when replacing saturated fatty acids in the diet (Matson \& Grundy, 1985; McDonald et al. 1989; Wardlaw et al. 1991; Valsta et al. 1992). Olive oil, however, has not been as consistent in this effect as other oleic-acid-rich oils (Sirtori et al. 1986; Mata et al. 1992). Differences in the effect of olive oil on plasma lipid levels and LDL-receptor-dependent uptake have been reported in animal models; Spady \& Dietschy (1988) found similar responses to olive oil and safflowerseed oil in the hamster whereas Fernandez \& McNamara $(1989,1991)$ found, in guinea-pigs, that responses to olive oil differed from those to maize oil. Similarly, hypercholesterolaemic responses to intake of olive oil compared wih polyunsaturated fat have been reported for rabbits and rats (Kris-Etherton et al. 1986; Beynen et al. 1987).

In the present studies we have demonstrated that intake of oleic-acid-rich rapeseed oil is more effective in lowering plasma LDL-cholesterol concentrations than olive oil (OL diet) or than a polyunsaturated fatty acid-enriched olive-oil diet (OL-S) indicating that rapeseed oil differs from olive oil in its effects on plasma LDL metabolism. It should be 
noted that plasma LDL-cholesterol levels in the OL-S and OL groups did not differ although there were significant differences in linoleic and oleic acid content. We have previously shown that intake of maize oil (rich in linoleic acid) significantly lowers plasma LDL-cholesterol levels compared with OL intake $(0.65$ (SD 0.11) mmol/1, $n 16 v .1 .26$ (SD 0.25) $\mathrm{mmol} / 1, n$ 14) (Fernandez et al. 1992), results which further support the hypothesis that OL has a hypercholesterolaemic effect in guinea-pigs, since an increase in the linoleic acid content of OL (OL-S diet) did not reverse this effect. In addition, the C-P diet had a much lower concentration of linoleic acid than maize oil $(240 \mathrm{v.} 480 \mathrm{~g} / \mathrm{kg})$ and both diets gave rise to lower plasma LDL-cholesterol concentrations than the OL diet. One could argue that the observed plasma LDL differences between the OL and the C-P groups were due to the higher concentration of linolenic acid in the C-P diet; however, since plasma LDL-cholesterol levels were not different between animals fed on the OL and the OL-S diets, the differences in linoleic acid content of the OL and C-P diets cannot fully explain the significant differences in plasma LDL-cholesterol levels. Further, we have found that linolenic and linoleic acids have identical plasma LDL-cholesterol-lowering effects in guinea pigs (D. J. McNamara, C. M. Montano and M. L. Fernandez, unpublished results) and therefore the more pronounced effect of rapeseed oil in reducing plasma LDLcholesterol levels cannot be solely attributed to the higher percentage of linolenic acid. We cannot discard the possibility that the lower plasma LDL-cholesterol levels and higher number of hepatic LDL receptors in animals fed on the C-P diet could be explained by the lower concentration of palmitic acid in the C-P diet compared with both the OL and the OL-S diets (44 and $35 \%$ lower respectively).

At present it is uncertain whether there is another component of olive oil, other than specific fatty acids, responsible for this effect. Nicolosi et al. (1991) reported a cholesterollowering effect of rice-bran oil in non-human primates which could not be explained by its fatty acid composition but was attributed rather to the non-saponifiable sterols present in the bran oil (Seetharamaiah \& Chandrasekhra, 1989). This situation is similar to the observed difference between rapeseed and olive oil which cannot be totally explained by fatty acid content.

When compared with olive oil (OL and OL-S diets), rapeseed oil in the diet reduced plasma LDL-cholesterol levels, increased LDL peak density, increased the number of hepatic LDL receptors, and up-regulated cardiac muscle LPL with a trend for higher LPL activity both in the skeletal and adipose tissues. In contrast, neither hepatic cholesterol concentrations nor hepatic cholesterol synthesis, measured as HMG-CoA reductase activity, were different between the rapeseed oil (C-P diet) and the olive-oil-based diets (OL and OL-S diets). Low values for hepatic HMG-CoA reductase activity with intake of oleicacid-rich diets compared with intake of polyunsaturated or saturated fat have been reported previously in guinea-pigs fed with olive oil (Fernandez \& McNamara, 1991, 1994). This decrease in hepatic HMG-CoA reductase is associated with a reduced hepatic cholesterol synthesis measured by $\left[{ }^{3} \mathrm{H}\right]$ water incorporation into sterols (Fernandez et al. 1990), which appears to be related to specific effects of monounsaturated fatty acids on hepatic cholesterol synthesis.

Previous studies in guinea-pigs have demonstrated that animals fed with maize oil (high polyunsaturated fat) have lower plasma LDL-cholesterol levels than animals fed with olive oil due to increased plasma LDL catabolism associated with an increase in the number of hepatic LDL receptors (Fernandez et al. 1992). In addition, LDL particles associated with the feeding of polyunsaturated fat were found to decrease atherosclerotic incidence in African green monkeys (Redel et al. 1985, 1986). In the present studies the increased number of hepatic LDL receptors in animals fed on the C-P diet would be predicted to lower plasma LDL-cholesterol levels. 
Although LPL is recognized as an important regulator of lipoprotein metabolism (Eckel, 1989), the effect of the type of dietary fatty acids on LPL activity is poorly understood. It is known, for example, that LPL activity is increased during high fat intake (Jansen $e t$ al. 1975; Weisenberg Delorme \& Harris, 1975; Kiens et al. 1987), probably due to increased availability of substrate, whereas when assessing LPL responses to the type of fat, intake of polyunsaturated compared with saturated fat results in higher LPL activity in the rat (Pawar \& Tidwell, 1968) and guinea-pig (Cryer et al. 1978). Feeding of rapeseed oil also results in higher cardiac lipase activities than olive oil in the rat (Weisenburg Delorme \& Harris, 1975). Although high fat compared with low fat, polyunsaturated compared with saturated fat, and rapeseed oil compared with olive oil increase LPL activity (Pawar \& Tidwell, 1968; Jansen et al. 1975; Weisenburg Delorme \& Harris, 1975; Cryer et al. 1978; Kiens et al. 1987), plasma LDL levels are higher in the former and lower in the latter situation suggesting that the contribution of LPL activity to plasma LDL concentrations differs depending on the dietary treatment. For example, in guinea-pigs the increases in cardiac LPL induced by high fat intake have been associated with cholesteryl-esterenriched VLDL which are readily converted to LDL particles resulting in an expanded plasma LDL pool (Fernandez et al. 1995). In contrast, the higher LPL activity with rapeseed oil intake observed in the present study might be related to an increased conversion of VLDL to smaller LDL particles which are rapidly cleared from plasma resulting in lower plasma LDL levels.

From these studies we conclude that the lowering of plasma LDL-cholesterol concentrations associated with the intake of rapeseed compared with olive oil does not result from modifications in hepatic cholesterol concentrations or hepatic cholesterol synthesis but is related to alterations in plasma lipoprotein remodelling and catabolism. What is also clear from these studies is that guinea-pigs respond to intake of monounsaturated fatty acid-rich rapeseed oil in a similar way to human subjects consuming diets enriched in monounsaturated fatty acids (Matson \& Grundy, 1985; McDonald et al. 1989; Mensink \& Katan, 1989) and that our previous observations in which maize-oil-fed animals had lower plasma LDL-cholesterol concentrations than animals fed with olive oil (Fernandez \& McNamara, 1991; Fernandez et al. 1992) relate to specific effects of the type of oil associated with specific fatty acids (mainly a higher content of palmitic acid) and possibly another component other than fatty acids in the oil, rather than to specific effects of oleic acid itself.

The authors wish to thank Mr Dong-Ming Sun for measuring hepatic cholesterol concentrations and Mr Henrik Steinberg for determination of plasma lipid levels. This work was supported by the American Heart Association, Arizona Affiliate and funds from the University of Arizona Agricultural Experimental Station.

\section{REFERENCES}

Allain, C. C., Poon, L. C., Chan, C. G. S., Richmond, W. \& Fu, P. C. (1974). Enzymatic determination of total serum cholesterol. Clinical Chemistry 20, 470-475.

Beynen, A. C., Versluis, A., Katan, M. B. \& Van Zutphen, L. F. M. (1987). Interaction of dietary cholesterol with the type of fat and fiber with regard to plasma cholesterol response in rabbits. Nutrition Reports International 35, 355-360.

Carr, T., Andresen, C. J. \& Rudel, L. L. (1993). Enzymatic determination of triglyceride, free cholesterol and total cholesterol in tissue lipid extracts. Clinical Biochemistry 26, 30-42.

Chan, J. K., Bruce, V. M. \& McDonald, B. E. (1991). Dietary $\alpha$-linolenic acid is as effective as oleic acid and linoleic acid in lowering blood cholesterol in normolipidemic men. American Journal of Clinical Nutrition 53, 1230-1240.

Cryer, A., Kirtland, J., Jones, H. M. \& Gurr, M. I. (1978). Lipoprotein lipase activity in the tissues of guinea pigs exposed to different dietary fats from conception to three months of age. Biochemical Journal 170, $169-172$. 
Daumerie, C. M., Woollett, L. A. \& Dietschy, J. M. (1992). Fatty acids regulate hepatic low density lipoprotein receptor activity through redistribution of intracellular cholesterol pools. Proceedings of the National Academy of Sciences, USA 89, 10797-10801.

Eckel, R. H. (1989). Lipoprotein lipase. A multifunctional enzyme relevant to common metabolic diseases. New England Journal of Medicine 320, 1060-1068.

Fernandez, M. L., Conde, K. A., Ruiz, L. R., Montano, C., Ebner, J. \& McNamara, D. J. (1995). Carbohydrate type and amount alter intravascular processing and catabolism of plasma lipoproteins in guinea pigs. Lipids 30 , $619-626$.

Fernandez, M. L., Lin, L. C. K. \& McNamara, D. J. (1992). Regulation of guinea pig plasma low density lipoprotein kinetics by dietary fat saturation. Journal of Lipid Research 33, 97-109.

Fernandez, M. L. \& McNamara, D. J. (1989). Dietary fat-mediated changes in hepatic apoprotein B/E receptor in the guinea pig: effect of polyunsaturated, monounsaturated, and saturated fat. Metabolism 38, $1094-1102$.

Fernandez, M. L. \& McNamara, D. J. (1991). Regulation of cholesterol and lipoprotein metabolism in guinea pigs mediated by dietary fat quality and quantity. Journal of Nutrition 121, 934-943.

Fernandez, M. L. \& McNamara, D. J. (1994). Dietary fat saturation and chain length modulate guinea pig hepatic cholesterol metabolism. Journal of Nutrition 124, 331-339.

Fernandez, M. L., Yount, N. Y. \& McNamara, D. J. (1990). Whole body cholesterol synthesis in the guinea pig. Effects of dietary fat quality. Biochimica et Biophysica Acta 1044, 340-348.

Goldstein, J. L., Basu, S. K. \& Brown, M. S. (1983). Receptor-mediated endocytosis of low density lipoprotein in cultured cells. Methods in Enzymology 98, 241-260.

Hegsted, D. M., Ausman, L. M., Johnson, J. A. \& Dallal, G. E. (1993). Dietary fat and serum lipids: an evaluation of the experimental data. Journal of Nutrition 57, 875-883.

Hegsted, D. M., McGandy, R. B., Myers, M. L. \& Stare, F. J. (1965). Quantitative effects of dietary fat on serum cholesterol in man. American Journal of Clinical Nutrition 17, 281-295.

Jansen, H., Hulsmann, W. C., van Zuylen-van Wiggen, A., Struijk, C. B. \& Houtsmuller, U. M. T. (1975). Influence of rapeseed oil feeding on the lipase activities of rat heart. Biochemical and Biophysical Research Communications 64, 747-751.

Keightley, D. D., Fisher, R. J. \& Cressie, N. A. C. (1983). Properties and interpretation of the Woolf and Scatchard plots in analyzing data from steroid receptor assays. Journal of Steroid Biochemistry 19, 1407-1412.

Keys, A., Anderson, J. T. \& Grande, F. (1965). Serum cholesterol response to changes in the diet. IV. Particular saturated fatty acids in the diet. Metabolism 14, 776-787.

Kiens, B., Essen-Gustavsson, B., Gad, P. \& Lithell, H. (1987). Lipoprotein lipase activity and intramuscular triglyceride stores after long-term high-fat and high-carbohydrate diets in physically trained men. Clinical Physiology 7, 1-9.

Kris-Etherton, P. M., Yo, C. Y. \& Fosmire, M. A. (1986). The effect of dietary fat saturation on plasma and hepatic lipoproteins in the rat. Journal of Nutrition 114, 1675-1682.

Lichtenstein, A. H., Ausman, L. M., Carrasco, W., Jenner, J. L., Gualtieri, L. J., Goldin, B. R., Ordovas, J. M. \& Schaefer, E. J. (1993). Effects of canola, corn, and olive oils on fasting and postprandial plasma lipoproteins in humans as part of a National Cholesterol Education Program Step 2 diet. Arteriosclerosis and Thrombosis 13, 1533-1542.

McDonald, B. E., Gerrard, J. M., Bruce, V. M. \& Corner, E. J. (1989). Comparison of the effect of canola oil and sunflower oil on plasma lipids and lipoproteins and on in vivo thromboxane $\mathbf{A}_{\mathbf{2}}$ and prostacyclin production in healthy young men. American Journal of Clinical Nutrition 50, 1382-1388.

McNamara, D. J. (1992). Dietary fatty acids, lipoproteins and cardiovascular disease. Advances in Food and Nutrition Research 36, 253-351.

Mata, P., Alvarez-Sala, L. A., Rubio, M. J., Nuno, J. \& De Oya, M. (1992). Effects of long-term monounsaturatedvs polyunsaturated-enriched diets on lipoproteins in healthy men and women. American Journal of Clinical Nutrition 55, 846-850.

Mattson, F. H. \& Grundy, S. M. (1985). Comparison of effects of dietary saturated, monounsaturated, and polyunsaturated fatty acids on plasma lipids and lipoproteins in man. Journal of Lipid Research 26, 194-202.

Mensink, R. P. \& Katan, M. B. (1989). Effect of a diet enriched with monounsaturated or polyunsaturated fatty acids on level of low-density lipoprotein cholesterol in healthy women and men. New England Journal of Medicine 321, 436-441.

Nicolosi, R. J., Ausman, L. M. \& Hegsted, M. A. (1991). Rice bran oil lowers serum total and low density lipoprotein cholesterol and apo B levels in non-human primates. Atherosclerosis 88, 133-142.

Nordstrom, J. L., Rodwell, V. W. \& Mitschelen, J. J. (1977). Interconversion of active and inactive forms of rat liver hydroxy-methyl-glutaryl Co A reductase. Journal of Biological Chemistry 252, 8924-8934.

Pawar, S. S. \& Tidwell, H. C. (1968). Effect of ingestion of unsaturated fat on lipolytic activity of rat tissues. Journal of Lipid Research 9, 334-336.

Rudel, L. L., Bond, M. G. \& Bullock, B. C. (1985). LDL heterogeneity and atherosclerosis in nonhuman primates. Annals of the New York Academy of Sciences 454, $248-253$.

Rudel, L. L., Park, J. S., Johnson, F. L. \& Babiak, J. (1986). Low density lipoproteins in atherosclerosis. Journal of Lipid Research 27, 465-474. 
Seetharamaiah, G. S. \& Chandrasekhra, N. (1989). Studies in hypocholesterolemic activity of rice bran oil. Atherosclerosis 78, 219-223.

Sirtori, C. R., Tremoli, E., Gatti, E., Montanari, G., Sirtori, M., Colli, S., Gianfranceschi, G., Maderna, P., Dentone, C. Z., Testolin, G. \& Galli, C. (1986). Controlled evaluation of fat intake in the Mediterranean diet: comparative activities of olive oil and corn oil on plasma lipids and platelets in high-risk patients. American Journal of Clinical Nutrition 44, 635-642.

Spady, D. K. \& Dietschy, J. M. (1988). Interaction of dietary cholesterol and triglycerides in the regulation of hepatic low density lipoprotein transport in the hamster. Journal of Clinical Investigation 81, 300-309.

Valsta, L. M., Jauhianinen, M., Aro, A., Katan, M. B. \& Mutanen, M. (1992). Effects of a monounsaturated rapeseed oil and a polyunsaturated sunflower oil diet on lipoprotein levels in humans. Arteriosclerosis and Thrombosis 12, 50-57.

Wardlaw, G. M. \& Snook, J. T. (1990). The effect of diets high in butter, corn oil, and high-oleic acid sunflower oil on serum lipids and apolipoproteins in men. American Journal of Clinical Nutrition 51, 815-821.

Wardlaw, G. M., Snook, J. T., Lin, M.-C., Puangco, M. A. \& Kwon, J. S. (1991). Serum lipid and apolipoprotein concentrations in healthy men on diets enriched in either canola oil or safflower oil. American Journal of Clinical Nutrition 54, 104-110.

Weisenburg Delorme, C. L. \& Harris, K. L. (1975). Effects of diet on lipoprotein lipase activity in the rat. Journal of Nutrition 105, 447-451. 